\title{
Small Bowel Obstruction Induced by Phytobezoar: A Case Report in Innocent Abdomen and Literature Review
}

\author{
Bréhima Traoré $1^{*}$, Djibril Traoré1, Modibo Coulibaly2 ${ }^{\circledR}$, Oumar Guindo ${ }^{3}$, Abdoulaye Traoré4, $^{4}$ \\ Fodé Mory Keita5, Kiffery Ibrahim Keita1, Korotimi Mallé1, Pierre Coulibaly6, \\ Aly Boubacar Diallo7, Dramane Cissé1, Dramane Samaké ${ }^{8}$, Pierre A. Togo ${ }^{9}$
}

\author{
${ }^{1}$ Department of General Surgery, Hôpital Sominé DOLO de Mopti, Mopti, Mali \\ ${ }^{2}$ Department of Biomedical Laboratory, Hôpital Sominé DOLO de Mopti, Mopti, Mali \\ ${ }^{3}$ Department of Public Health, Hôpital Sominé DOLO de Mopti, Mopti, Mali \\ ${ }^{4}$ Department of Anesthesia and Resuscitation, Hôpital Sominé DOLO de Mopti, Mopti, Mali \\ ${ }^{5}$ Department of Surgery, Polyclique des Armées de Kati, Koulikoro, Mali \\ ${ }^{6}$ Department of Gynecology and Obstetrics, Hôpital Sominé DOLO de Mopti, Mopti, Mali \\ ${ }^{7}$ Department of General Surgery, Hôpital Régional de Sikasso, Sikasso, Mali \\ ${ }^{8}$ Department of Medicine, Hôpital Sominé DOLO de Mopti, Mopti, Mali \\ ${ }^{9}$ Faculty of Medicine and Odonto Stomatology, University of Sciences Technics and Technologies de Bamako, Bamako, Mali \\ Email: ^drbrehimat2@gmail.com,dtdjibsonl28@gmail.com, modibocoulibaly@yahoo.com, barugdo@yahoo.fr, \\ ngoaabdoulaye@yahoo.fr, keitaf70@yahoo.fr, kifferyibrahim@gmail.com, mallekoro@gmail.com,coulipierre@yahoo.fr, \\ dialloalyboubacar83@gmail.com, djennecisse@yahoo.fr,dramanesamake@rocketmail.com, ap.togo@yahoo.fr
}

How to cite this paper: Traoré, B., Traoré, D., Coulibaly, M., Guindo, O., Traoré, A., Keita, F.M., Keita, K.I., Mallé, K., Coulibaly, P., Diallo, A.B., Cissé, D., Samaké, D. and Togo, P.A. (2021) Small Bowel Obstruction Induced by Phytobezoar: A Case Report in Innocent Abdomen and Literature Review. Surgical Science, 12, 187-195. https://doi.org/10.4236/ss.2021.126020

Received: May 15, 2021

Accepted: June 26, 2021

Published: June 29, 2021

Copyright $\odot 2021$ by author(s) and Scientific Research Publishing Inc. This work is licensed under the Creative Commons Attribution International License (CC BY 4.0).

http://creativecommons.org/licenses/by/4.0/

(c) (i) Open Access

\begin{abstract}
Introduction: Small bowel obstruction (SBO) is defined as a complete and persistent cessation of the transit of materials and gases. It occurs in a segment of the digestive tract located between the pylorus and the colorectal junction. Herein, we report a case of small bowel obstruction (SBO) following excessive consumption of wild grapes with no previous abdomen medical or surgical history. Presentation of case: A 65-year-old male farmer presented with cessation of materials and gas associated with vomiting of food and then bilious. The abdomen was bloated and painful on palpation with a moving, painful mass in the left iliac fossa. The hypothesis of acute occlusion of the colon was retained and confirmed on the X-Ray which showed a dilation of small bowel with air-fluid levels. The diagnostic of acute SBO was retained. We performed urgently a median laparotomy. We found the dilation of the loops from the jejunum to the sigmoid colon with a compact mass at the sigmoid colon of $15 \mathrm{~cm}$ in length and $6 \mathrm{~cm}$ in diameter. We proceeded to crush the mass that was made up with wild grape seed fecal, and push it back to the rectum. The phytobezoar made up with wild grape seeds was extracted through the anus with the fingers after anal dilation. After extraction of the bezoar, the patient's
\end{abstract}


complaints completely subsided. Discussion: SBO is a frequent emergency surgical pathology. SBO induced by phytobezoar often occurs in patients with abdomen surgery history. However, it is particularly rare in virgin abdomen. Conclusion: This case report aims to raise awareness of phytobezoar as a cause of SBO in elderly even though without abdomen surgery history.

\section{Keywords}

Small Bowel Obstruction, Phytobezoars, Innocent Abdomen

\section{Introduction}

Phytoezoars are aggregates of indigested food material that accumulate in the gastroenteric tract, especially in the stomach and in the narrowest points of the small bowel. Small bowel obstruction (SBO) is defined as a complete and persistent cessation of the transit of materials and gases. It occurs in a segment of the digestive tract located between the pylorus and the colorectal junction [1]. SBO associated with excessive fruit consumption is rare, however, cases have been reported in the literature. Bedioui $\mathrm{H}$. et al. reported that $4 \%$ of SBO, was induced by phytobezoars [2]. This mechanical alimentary tract obstruction due to phytobezoar mainly occurred in patients who have undergone previous gastric operation [2] [3] [4] and excessive consumption of prickly pears (cactus figs) [2]. This form of bowel obstruction occurs in both sexes, but it is typically seen in men [2] [5] [6]. The diagnosis is both clinical and radiological. The $\mathrm{x}$-ray of the abdomen is the first-line diagnostic examination [7]. The computed tomography scan (CT) remains the goal standard and provides information on the cause, location and vitality of the handles [8]. The Single-Balloon enterostomy has also been used in the diagnosis and treatment of some patients [9]. Due to its medico-surgical emergency nature, the management of medico-surgical intestinal obstruction frequently requires a multidisciplinary team [10] [11] [12]. Herein, we report the clinical, diagnostic, surgical, and therapeutic features of a case of intestinal obstruction induced by excessive consumption of wild grape seeds that we encountered for the first time in our practice as a surgeon for more than 20 years ago.

\section{Observation}

Mr. OT, 65 years old, a farming profession, was urgently admitted in our department of surgery for acute abdominal pain.

\subsection{History of the Disease}

The onset of symptoms dated back to 3 days marked by intermittent tingling-type abdominal pain. Several analgesic-based treatments at the local health center, but also traditional medicine based on a plant decoction with a slight improvement had been carried out. The pain had been accentuated 24 hours 
earlier, accompanied by stopping the materials and then vomiting of food and then bilious, motivating his emergency evacuation to our hospital structure.

\subsection{Questioning and Physical Examination}

On admission, questioning rediscovered the notion of constipation after consuming a large number of wild grapes for 72 hours. To this was added abdominal pain accompanied by vomiting of food and then bilious. The medical and surgical history was unremarkable. At the general examination, we note an index of the World Health Organization at 02, the Glasgow score at 15/15, the blood pressure at $130 \mathrm{~mm} \mathrm{Hg} / 70 \mathrm{~mm} \mathrm{Hg}$, the temperature at $37.5^{\circ} \mathrm{C}$, the weight at 65 $\mathrm{kg}$, heart rate at 85 beats per $\mathrm{mm}$ and respiratory rate at $22 \mathrm{cycles} / \mathrm{mm}$. The general condition is satisfactory, the conjunctivae well colored and the presence of folds of skin dehydration was noted.

On physical examination, the abdomen was bloated, distended without a scar from the laparotomy. On palpation, there was a diffuse pain in the abdomen with a sensation of a mobile and painful mass in the left iliac fossa. The hernial orifices were free. Percussion found a diffuse tympanism throughout the abdomen while auscultation of the abdomen found air-fluid noises. As for the cardiopulmonary auscultation, it was unremarkable. On proctologic examination the anal margin was clean with a hemorrhoidal layer at 6 o'clock, with no fissure or anal fistula. On digital rectal examination, the bulb was empty and painless. There were no palpable mass and the finger cot was clean. There was the existence of pain in the cul de sac on the left. Taking all this into consideration, clinical diagnosis of SBO due to phytobezoar was the most plausible.

At all, This is a 65-year-old patient, resident in Bankass (Mopti) with no particular history referred by the local health center for pain and abdominal bloating accompanied by bilious vomiting and stopping of materials and gas, with no particular history.

Faced with this clinical picture, three diagnostic hypotheses were put forward: Invagination of the sigmoid colon, colonic tumor, and colonic occlusion on fecaloma.

\section{Preoperative Resuscitation}

It consisted of an infusion of 4 liters of solutions ( 2 liters of saline serum and 2 liters of Ringer lactate). At the same time, the patient also received $2 \mathrm{~g}$ of ceftriaxone, $1 \mathrm{~g}$ of metronidazole and $1 \mathrm{~g}$ of paracetamol as an infusion. An indwelling bladder catheter and a nasogastric catheter were placed. The preoperative workup concerned the complete blood count: the hemoglobin level was 15.6 $\mathrm{g} / \mathrm{dL}$, the white blood cells were $13.8(10)^{3} \mu \mathrm{L}$. The serum creatinine was 1.05 $\mathrm{mg} / \mathrm{dL}$ and the blood group was $\mathrm{O}$ Rhesus positive (Table 1 ). X-ray of the abdomen unprepared upright from the front showed hydro areal levels (Figure 1(a)). The computed tomography (CT) scan was not performed due to its unavailability at the time of the case. There were dilated small bowel loops on Supine X-ray abdomen. 


\section{Surgical Management and Patient Outcome}

We performed a midline supra and sub umbilical laparotomy. After coeliotomy, exploration found a mass $15 \mathrm{~cm}$ long by $6 \mathrm{~cm}$ in diameter at the level of the sigmoid colon (Figure 1(b)). The colonic wall was normal. Palpation and pinching of the mass between the fingers showed that the mass was a fecal impaction made up of clumped fruit seeds obstructing the colonic lumen (Figure 1(b)).

We proceeded to a digital crush of the faecolith which was made of wild grape seeds and its progressive repression from the sigmoid towards the rectum. The colonic handle was healthy. After the peritoneal cleansing with physiological saline, enterotomy was closed in two layer and laparotomy in one layer. After the dressing, the patient was placed in a gynecological position, with anal dilation and removal of the faecolith on the finger (Figure 1(c)). The preoperative duration was 55 minutes during which, the blood loss was evaluated at nearly 100 centiliters.

Postoperatively, the patient was rehydrated by an infusion of 3 liters of solution per day for 3 days. This rehydration was accompanied by antibiotic prophylaxis based on $2 \mathrm{~g}$ of ceftriaxone and $1 \mathrm{~g}$ of metronodazole per day for 2 days. Paracetamol $500 \mathrm{mg}$ was infused every 8 hours for 3 days. The postoperative follow-up was simple: liquid food was prescribed on the first postoperative day, semi-liquid the second day after the resumption of digestive transit and normal food from the third day.

Table 1. Preoperative laboratory testing.

\begin{tabular}{ccc}
\hline \multirow{2}{*}{ Laboratory tests } & \multicolumn{2}{c}{ Tests values and reference interval } \\
\cline { 2 - 3 } & Value & Reference interval \\
\hline With Blood Cell $(\mu \mathrm{L})$ & $13.8^{*} 10^{3}$ & $4-10^{\star} 10^{3}$ \\
Hemoglobin $(\mathrm{g} / \mathrm{dL})$ & 15.6 & $13-18$ \\
Blood Creatinine $(\mathrm{mg} / \mathrm{dL})$ & 1.05 & $0.57-1.36$ \\
Blood group/Rhesus $(\mathrm{ABO} /$ Rhesus system) & Opositive & $-\cdots$
\end{tabular}

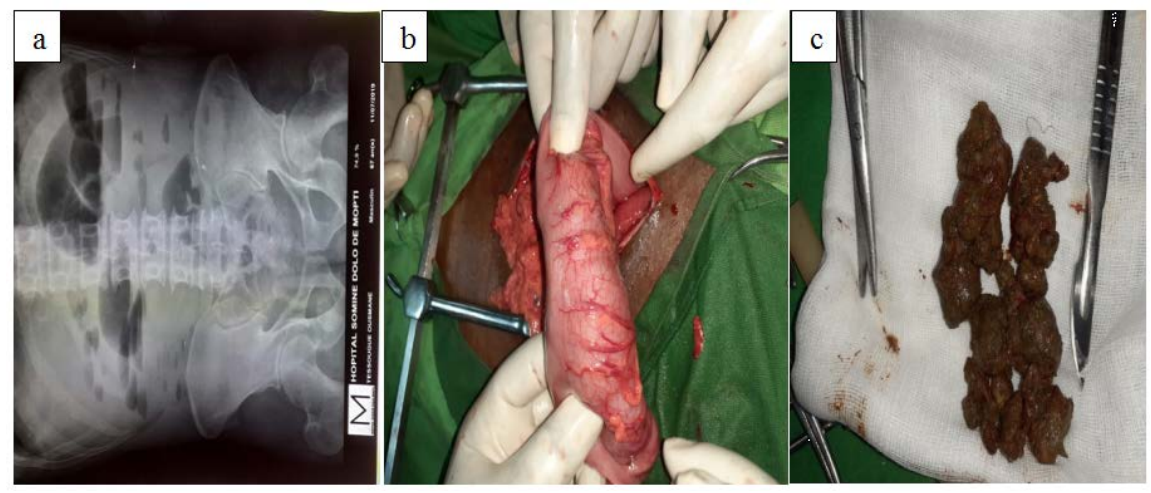

Figure 1. (a) X-ray of the abdomen, (b) Sigmoid colon filled and obstructed by fecal impaction made with seeds of wild grapes. Phytobezoar after beiing removed through enterotomy, (c) Fecaloma made with wild grape seeds. 
The patient was discharged on the $8^{\text {th }}$ postoperative day. The one-month follow-up did not note any postoperative complications.

\section{Discussion}

Phytobezoar is a well-known although uncommon cause of mechanical alimentary tract obstruction. We herein report the case of a 65 -year-old man and discuss the epidemiology, diagnosis, surgical and therapeutic management and the evolution. Mainly phytobezoar occurs in old patients who have undergone previous gastric operation [1] [3] [13]. However, our patient presented with an innocent abdomen that had not been operated on in the past. Other authors have also reported cases of intestinal obstruction induced by phytobezoar in innocent abdomen [14] [15]. There are four types of bezoars: phytobezoars, trichobezoars, pharmacobezoars and lactobezoars. The most common type is phytobezoars, which are composed of undigested fiber from vegetables or fruits especially persimmons [16]. Our case was due to a wild grape phytobezoar. It can occur with all types of fruit with grains rich in fiber and cellulose: persimmon [17], chestnuts [18], aloe Vera [19], mushroom [20], mango [21], potato and broccoli [22].

SBO induced by phytobezoar occurs both in the two sexes but it is predominant in man. Our patient was a male farmer. Several author have reported a sex-ratio superior to 1 [2] [14]. In contrast, Wang PY et al., 2015 reported a sex-ratio of 0.59 [5].

The elderly are the most affected [2] [14] as in our case, the patient was in his sixties. However, children are also prone to do SBO with phytobezoar [16].

Generally, the cases of phytobezoar are observed during autumn and winter corresponding to the period of high consumption of fruits rich in fiber and cellulose [5]. Our case also occurred in winter corresponding to the wild fruit season in Mali and fieldwork which could lead to increased consumption of these fruits by farmers. The large consumption and the lack of information regarding the risks in association with previous gastric surgery and older age could play a major role in the recent increase of the incidence [3] [5].

The pathogenesis of an SBO relies on an obstruction that can cause the material inside the bowel to back up into the stomach. This causes nausea and vomiting of dark green bile known as bilious vomiting. The bowel preceding the obstruction becomes large, dilated, and filled with the fluid and air that would otherwise move forward. This causes bloating known as abdominal distention. Severe pain or fever may be a sign that the bowel is not receiving enough blood or may be dead [1]. Our patient also showed an intermittent tingling-type abdominal pain, accompanied by stopping the materials and then vomiting of food and then bilious.

In our case, the diagnosis was made thanks to the clinic, the standard X-ray (Figure 1(a)). Abdominal ultrasound and computed tomography were not performed. Otherwise, the diagnostic of SBO is based on a doctor's examination accompanied by blood tests and an X-ray or abdomen ultrasonography. Often, 
computed tomography (CT) scan is used to confirm the diagnosis [1]. Le CT scan remains the goal standard and provides information on the cause, location and vitality of the intestinal loops [5] [7] [8]. Patients without any history of bowel surgery or without a hernia found on examination should undergo a CT scan to exclude cancer as a possible cause of the obstruction [1]. Bedioui $\mathrm{H}$ et al., 2008 [2] have used the CT scans in three patients (20.0\%), who were successfully treated with gastric aspiration, thereby avoiding surgery. In a metanalysis study covering 45 studies, the pooled sensitivity and specificity of CT for SBO were 91\% (95\% CI: 84\%, 95\%) and 89\% (95\% CI: 81\%, 94\%), respectively [8]. Single-Balloon Enteroscopy (SBE) was also successful used to diagnosis and to treat phytobezoar induced small bowel obstruction [9] [23].

In the decision-making process to choose which patient needs surgery and which does not, patients with clinical signs of strangulation or peritonitis underwent immediate surgery. The rest of the patients should receive conservative treatment. However, some patients after conservative treatment showed persisting or progressive symptoms and absence of contrast agent in the colon after 12

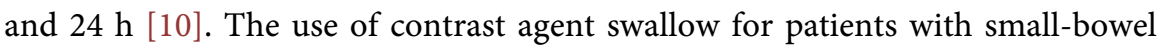
obstructions enabled a timely and very accurate differentiation between patients qualifying for conservative and operative treatment [10]. Conservative treatment is carried out by gastric aspiration using a nasogastric tube accomplished by inserting a nasogastric (NG) tube that suctions fluid from the stomach can often solve the problem, as this was the case in [1]. However, in some cases, like ours, that is not enough and it is necessary to proceed to exploratory laparotomy and enterotomy to extract the faecolith [4].

In our case, we performed a midline supra and sub umbilical laparotomy. After coeliotomy, exploration found a mass $15 \mathrm{~cm}$ long by $6 \mathrm{~cm}$ in diameter at the level of the sigmoid colon (Figure 1(b)). A digital crush of the faecolith which was made of wild grape seeds and its progressive removed from the sigmoid towards the rectum. After the peritoneal cleansing with physiological saline, enterotomy was closed in two-layer and laparotomy in one layer. After the dressing, the patient was placed in a gynecological position, with anal dilation and removal of the faecolith on the finger (Figure 1(c)). This technique allows us to avoid opening the colon by; digestive endoscopy (colonoscopy) could not only help to make the diagnosis but also to extract the faecolith thus avoiding the patient a laparotomy if the patient is seen at the stage of severe constipation. An antibio-prophylaxis based on $2 \mathrm{~g}$ of ceftriaxone and $1 \mathrm{~g}$ of metronodazole per day for 2 days was established. Paracetamol $500 \mathrm{mg}$ was infused every 8 hours for 3 days. Laparotomy was also performed in 12 patients $(80.0 \%)$ to allow digital fragmentation of the bezoar, which was then washed into the colon [2]. The postoperative follow-up in our case was simple: liquid food was prescribed on the first postoperative day, semi-liquid the second day after the resumption of digestive transit and normal food from the third day. The patient was discharged on the $8^{\text {th }}$ postoperative day. Usually, an SBO resolves after a few days with less morbidity and mortality. Bedioui H. et al., 2008 [2] reported no postoperative deaths 
and morbidity was about 13\%. Anupama PK et al., 2013 [4] reported that their patient was started on liquids orally on $5^{\text {th }}$ day followed by soft diet subsequently and was discharged on $10^{\text {th }}$ postoperative day. Patient was on follow up for one month which was found uneventful. Since phytobezoars could play important role in the small bowel obstruction due to the ingestion of great quantities of different fruits containing great amounts of cellulose, this case report calls for restriction of the consumption of wild grapes fruit in rural sexagenarian even though with no history of abdomen surgery.

\section{Conclusion}

Small Bowel obstruction is a medico-surgical emergency. The clinical form occurring as a result of obstruction by fruit seed feces is rare but could lead to life threatening issue. Therefore, their early management deserves special attention especially for patients referred from rural areas during the season of wild grapes.

\section{Acknowledgements}

We are grateful to the patient of this study; the staff of Mopti Hospital, Mopti, Mali, Academic Hospital, Hôpital Gabriel Touré, Bamako, Mali for their assistance.

\section{Statement of Informed Consent}

The patient gave fully informed written consent prior to this publication.

\section{Conflicts of Interest}

The authors declare no conflicts of interest regarding the publication of this paper.

\section{References}

[1] Baiu, I. and Hawn, M.T. (2018) Small Bowel Obstruction. JAMA, 319, 2146. https://doi.org/10.1001/jama.2018.5834

[2] Bedioui, H., Daghfous, A., Ayadi, M., Noomen, R., Chebbi, F., Rebai, W., Makni, A., Fteriche, F., Ksantini, R., Ammous, A., Jouini, M., Kacem, M. and BenSafta, Z. (2008) A Report of 15 Cases of Small-Bowel Obstruction Secondary to Phytobezoars: Predisposing Factors and Diagnostic Difficulties. Gastroentérologie Clinique et Biologique, 32, 596-600. https://doi.org/10.1016/j.gcb.2008.01.045

[3] Rubin, M., Shimonov, M., Grief, F., Rotestein, Z. and Lelcuk, S. (1998) Phytobezoar: A Rare Cause of Intestinal Obstruction. Digestive Surgery, 15, 52-54. https://doi.org/10.1159/000018586

[4] Anupama, P.K., Sreekar, P.A. and Bharati, H.V. (2013) Phytobezoar: A Rare Cause of Small Bowel Obstruction. Journal of Clinical and Diagnostic Research, 7, 2298-2299.

[5] Wang, P.Y., Wang, X., Zhang, L., Li, H.F., Chen, L., Wang, X. and Wang, B. (2015) Bezoar-Induced Small Bowel Obstruction: Clinical Characteristics and Diagnostic Value of Multi-Slice Spiral Computed Tomography. World Journal of Gastroenterology, 21, 9774-9784. https://doi.org/10.3748/wjg.v21.i33.9774 
[6] De Cesare, A., Fiori, E., Bononi, M. and Ferraro, D. (2015) Phytobezoar Induced Small Bowel Obstruction Associated with a Concomitant Gastric Phytobezoar and Ulcer in an Elderly Woman. Annali Italiani di Chirurgia, 86, 70-77. https://pubmed.ncbi.nlm.nih.gov/25817461/

[7] Paulson, E.K. and Thompson, W.M. (2015) Review of Small-Bowel Obstruction: The Diagnosis and When to Worry. Radiology, 275, 332-342. https://doi.org/10.1148/radiol.15131519

[8] Li, Z., Zhang, L., Liu, X., Yuan, F. and Song, B. (2019) Diagnostic Utility of CT for Small Bowel Obstruction: Systematic Review and Meta-Analysis. PLOS ONE, 14, e0226740. https://doi.org/10.1371/journal.pone.0226740

[9] Ma, T., Liu, G.Q. and Zuo, X.L. (2017) Phytobezoar-Induced Small-Bowel Obstruction Successfully Diagnosed and Treated by Single-Balloon Enteroscopy. Clinical Gastroenterology and Hepatology, 15, A23-A24.

https://doi.org/10.1016/j.cgh.2017.03.029

[10] Kuehn, F., Weinrich, M., Ehmann, S., Kloker, K., Pergolini, I. and Klar, E. (2017) Defining the Need for Surgery in Small-Bowel Obstruction. Journal of Gastrointestinal Surgery, 21, 1136-1141. https://doi.org/10.1007/s11605-017-3418-x

[11] Grundmann, R.T., Petersen, M., Lippert, H. and Meyer, F. (2010) The Acute (Surgical) Abdomen-Epidemiology, Diagnosis and General Principles of Management. Zeitschrift für Gastroenterologie, 48, 696-706.

https://doi.org/10.1055/s-0029-1245303

[12] Long, B., Robertson, J. and Koyfman, A. (2019) Emergency Medicine Evaluation and Management of Small Bowel Obstruction: Evidence-Based Recommendations. The Journal of Emergency Medicine, 56, 166-176. https://doi.org/10.1016/j.jemermed.2018.10.024

[13] Masri, R., Mahli, N., Alobied, M., Moahed, R. and Fadilh, R. (2018) Small Bowel Obstruction Due to a Phytobezoar Thirty Years after Roux-en-Y Gastrojejunostomy: A Case Report. International Journal of Surgery Case Reports, 50, 116-118. https://doi.org/10.1016/j.ijscr.2018.07.023

[14] Ng, Y.Y.-R., Ngu, J.C.-Y. and Wong, A.S.-Y. (2108) Small Bowel Obstruction in the Virgin Abdomen: Time to Challenge Surgical Dogma with Evidence. ANZ Journal of Surgery, 88, 91-94. https://doi.org/10.1111/ans.13714

[15] Tiwari, A., Gupta, V., Hazrah, P., Chaudhary, A.K. and Lal, R. (2013) Phytobezoar: a Rare Cause of Acute Small Bowel Obstruction in an Innocent Abdomen. Arquivos Brasileiros de Cirurgia Digestive, 26, 342-343. https://doi.org/10.1590/S0102-67202013000400020

[16] Glatstein, M., Danino, D., Rimon, A., Keidar, S. and Scolnik, D. (2013) An Unusual Cause of Small Bowel Obstruction in a Child: Ingested Rhubarb. Case Reports in Surgery, 2013, Article ID: 497214. https://doi.org/10.1155/2013/497214

[17] Yamamoto, M., Yamamoto, K., Bian, X., Guo, Q., Sasaki, T., Yamamoto, F. and Yamamoto, H. (2018) Small Bowel Obstruction Caused by Dried Persimmon. Case Reports in Gastroenterology, 12, 147-152. https://doi.org/10.1159/000488527

[18] Ravindra, R.K., Das, A., Chew, G.L. and Daniel, E. (2019) Small Bowel Obstruction with Multiple Perforations Post Chestnut Ingestion. BMJ Case Reports, 12, Article ID: 227999. https://doi.org/10.1136/bcr-2018-227999

[19] Hong, I.T., Cha, J.M., Ki, H.J., Kwak, M.S., Yoon, J.Y., Shin, H.P., Jeoun, J.W. and Choi, S.I. (2017) Small Bowel Obstruction Caused by Aloe vera Bezoars: A Case Report. The Korean Journal of Gastroenterology, 69, 312-315. 
https://doi.org/10.4166/kjg.2017.69.5.312

[20] Hamzah, A.A., Keow, C.K., Syazri, A., Mallhi, T.H., Khan, A.H., Khan, Y.H. and Adnan (2017) Mushroom Bezoar Causing Small Bowel Obstruction. Journal of College of Physicians and Surgeons Pakistan, 27, S13-S15.

https://pubmed.ncbi.nlm.nih.gov/28302231/

[21] Islam, S., Saroop, S., Bheem, V., Harnarayan, P. and Naraynsingh, V. (2018) Mango Seed Causing Acute Large Bowel Obstruction in Descending Colon-World's First Reported Case. International Journal of Surgery Case Reports, 51, 125-129. https://doi.org/10.1016/j.ijscr.2018.08.028

[22] Serrano, K.D. and Tupesis, J.P. (2013) Small Bowel Obstruction from Potato and Broccoli Phytobezoar Mimicking Mesenteric Ischemia. The Journal of Emergency Medicine, 44, 79-81. https://doi.org/10.1016/j.jemermed.2011.06.018

[23] Park, E.Y., Baek, D.H., Lee, B.E., Kim, G.H. and Song, G.A. (2020) Large Jejunal Phytobezoar with Small Bowel Obstruction Treated by Single-Balloon Enteroscopy: A Case Report. Clinical Endoscopy, 2020, 215. https://doi.org/10.5946/ce.2020.215 